\title{
Upright kneeling position during second stage of labor: a pilot study
}

\author{
Anjali Dabral, Pallavi Pawar, Rekha Bharti*, Archana Kumari, \\ Achla Batra, Renu Arora
}

Department of Obstetrics and Gynecology, Vardhman Mahavir Medical College and Safdarjung Hospital, New Delhi, India

Received: 10 December 2017

Accepted: 21 December 2017

*Correspondence:

Dr. Rekha Bharti,

E-mail: rekhabharti@gmail.com

Copyright: (c) the author(s), publisher and licensee Medip Academy. This is an open-access article distributed under the terms of the Creative Commons Attribution Non-Commercial License, which permits unrestricted non-commercial use, distribution, and reproduction in any medium, provided the original work is properly cited.

\begin{abstract}
Background: Women delivering in upright position have shorter labour due to efficient and stronger contractions with faster descent of foetal head. The present study aimed to find out effect of upright kneeling position in the second stage of labour on maternal and foetal outcome and assess patients' satisfaction.

Methods: The study was carried out in a tertiary care hospital of North India from October 2012 to February 2014. Low risk women admitted in early labour were divided into two groups, women delivering in kneeling position and in supine position. The outcome measures studied were, duration of second stage of labour, mode of delivery, $2^{\text {nd }}$ degree perineal tears, Apgar scores at 5 minutes, NICU admission rate and patient satisfaction.

Results: The mean duration of second stage of labour in kneeling group was shorter by 14.901 minutes. The rate of vaginal delivery was comparable for both primigravidas and multigravida in kneeling and supine groups, RR: 2.275, 95\% CI (0.7872-6.5831) and RR: 1.633 , 95\% CI (0.393-6.775). Primigravidas had more $2^{\text {nd }}$ degree perineal tears in kneeling group as compared to supine, RR 4.191, 95\% CI (1.54 to 11.41). No difference in Apgar scores $>7$ at 5 minutes was observed in both groups, however, significantly lesser babies in kneeling group were admitted in NICU, RR $0.246,95 \%$ CI (0.079 to 0.761). There was no difference on comparing satisfaction scores of primigravidas and multigravida in both supine and kneeling position.

Conclusions: Kneeling position reduces the duration of second stage of labour and NICU admissions.
\end{abstract}

Keywords: Apgar Score, Delivery, Labor, Neonatal Intensive Care Unit, Patient satisfaction, Second stage

\section{INTRODUCTION}

There is no ideal position for labour and delivery, the standard recommendation is to encourage and support the parturient to deliver in the position she feels most comfortable in. ${ }^{1,2}$ Although international guidelines advice against being recumbent or supine for long periods of time during labour, women are motivated to deliver in the supine position at most delivery centres in India. Women delivering in the supine position experience comparatively painful prolonged labors with increased incidence of foetal distress due to more aortocaval compression by the gravid uterus. ${ }^{1-5}$ However, supine position in the second stage of labour is favoured by most obstetricians as they are trained to take delivery in this position. It allows them to monitor the labour process better with ease of providing anaesthesia, enables them to give proper perineal support in the second stage of labour, and conduct operative vaginal deliveries.

Upright labour positions have several physiological advantages over the supine position. Historically women were instinctively adopting upright positions for delivery as they experienced stronger, more efficient and less 
painful uterine contractions, faster descent of foetal head due to gravitational pull, improved alignment of foetal passage, and increase in the pelvic outlet diameters, hence shorter labour duration. ${ }^{1,2,4,6,7}$ These positions also decrease the need for operative vaginal deliveries and caesarean section rate. .,2,4,6 $^{-1}$

Delivery in squatting position has been described to be associated with higher degree of intrapartum and postpartum pain which is attributed to the tissue edema caused by constant pressure on the pelvic floor. ${ }^{8}$ This position ideally requires a birthing stool or chair. Therefore, we found taking deliveries in the kneeling position most feasible on the standard delivery tables available in the maternity hospitals. Moreover, amongst the various upright positions, kneeling has been described as the most comfortable second stage position. ${ }^{8}$ There is also a paucity of Indian data regarding delivering in kneeling position.

The present study was designed to find out the effect of kneeling position during the second stage of labour on the duration of second stage. It also aimed to observe the feto-maternal outcome and satisfaction of women with delivery in this position.

\section{METHODS}

The study was carried out from October 2012 to February 2014, at a North India tertiary care hospital. The women admitted during early labour were screened on 2 fixed days of the week and eligible candidates were included in the study after taking written informed consent. Before starting the study, clearance was taken from the Institutional Ethical committee. Women aged 18 to 40 years with singleton term live pregnancy who were able to understand and follow instructions for the change in the labour position were included in the study. Women with previous caesarean sections, premature labour, chorioamnionitis, hypertensive disorders of pregnancy, antepartum hemorrhage, severe anemia, epilepsy, heart disease, hypothyroidism, gestational diabetes mellitus, cephalopelvic disproportions and malpresentations were excluded from the study.

Women recruited in the study were divided into Group A and $\mathrm{B}$ using computer generated random table. Women in group A were delivered in kneeling position. In this position the women rested on their knees and held onto the handle bars at the side of the table, Figure 1. Women in group B delivered in supine position; here women lay on their back with legs flexed at hip and knees and feet resting on the bed.

All deliveries were conducted by the same person. FHS was monitored by Doptone monitor. In the kneeling position the patient was made to sit at the edge of the table in the second stage of labour. After delivery of head, patient was shifted to supine position. Active management of the third stage was done in both the groups. The women, who were recruited to kneeling position and were not willing to continue the labour process in that position, were excluded from the study group.

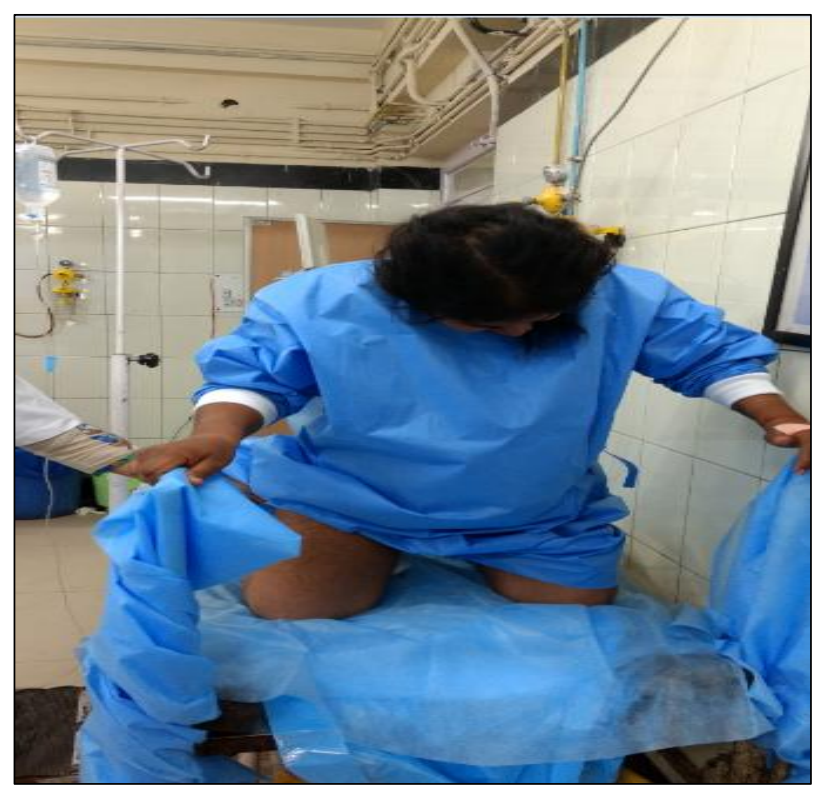

Figure 1: Kneeling position.

The primary outcome measures were duration of second stage of labour and the mode of delivery while the secondary outcome measures were perineal tears, patient satisfaction, and foetal outcomes measured by APGAR scores at 5 minutes and NICU admission rate. Measurement of patient satisfaction was subjective observation in which women were asked about their comfort of delivering in the particular labour position.

Statistical analysis was done using t test for Quantitative data and Chi-square test and Fisher test for Qualitative data.

\section{RESULTS}

A total of 360 women were recruited in the study, 38 women in the kneeling group were not comfortable in that position and 22 had caesarean section in the first stage of labour, thus were excluded from the study (Figure 2). The mean age of women in kneeling and supine groups was comparable, 24.23 \pm 3.04 and $23.60 \pm 2.85$ years respectively, $\mathrm{p}=0.22$. The gestational age was also comparable in both groups, $\mathrm{p}=0.157$, Table1. Most of the women in the kneeling group were multigravida, $68 \%$ compared to $42.7 \%$ in supine group, $\mathrm{p}<0.01$.

The mean duration of second stage of labour in kneeling group was shorter by 14.901 minutes. The rate of vaginal delivery was comparable for both primigravidae and multigravidae in kneeling and supine groups, RR-2.275, 95\% CI (0.7872-6.5831) and RR-1.633, 95\% CI (0.393- 
6.775), Table 2. Normal vaginal delivery rate was higher in kneeling position as compared to supine position, although the difference was not statistically significant, $89.6 \%$ Vs $79 \%$ for primigravidae, RR-2.275; 95\% CI 0.7872 to 6.5831 and $96.1 \%$ Vs $93.75 \%$ for multigravidae, RR-1.633; $95 \%$ CI 0.393 to 6.775 , Table 3.

Primigravidae had more $2^{\text {nd }}$ degree perineal tears in kneeling group as compared to supine, RR 4.191, 95\% CI (1.54 to 11.41$)$, Table 4.
Table 1: Period of gestation of women in kneeling and supine group.

\begin{tabular}{|lll|ll|}
\hline $\begin{array}{l}\text { Period of } \\
\text { gestation } \\
\text { (weeks) }\end{array}$ & Number & $\%$ & Number & $\%$ \\
\hline $37+0-37+6$ & 31 & $20.7 \%$ & 34 & $22.7 \%$ \\
\hline $38+0-38+6$ & 26 & $17.3 \%$ & 34 & $22.7 \%$ \\
\hline $39+0-39+6$ & 51 & $34.0 \%$ & 56 & $37.3 \%$ \\
\hline $40+0-40+6$ & 42 & $28.0 \%$ & 26 & $17.3 \%$ \\
\hline
\end{tabular}

Table 2: Duration of second stage of labour in kneeling and supine group.

\begin{tabular}{|c|c|c|c|c|c|c|c|}
\hline \multirow{2}{*}{ Parity } & & \multicolumn{4}{|c|}{ Duration of second stage (minutes) } & \multirow{2}{*}{ Mean (minutes) } & \multirow{2}{*}{$\begin{array}{l}\text { Mean difference } \\
\text { (minutes) }\end{array}$} \\
\hline & & $<\mathbf{1 5}$ & 15-30 & $30-45$ & $>45$ & & \\
\hline \multirow{2}{*}{ Primigravida } & Kneeling $\mathrm{N}=48$ & 8 & 25 & 6 & 9 & $29.54 \pm 15.53$ & \multirow{2}{*}{-12.17} \\
\hline & Supine $N=86$ & 7 & 20 & 22 & 37 & $41.70 \pm 16.29$ & \\
\hline \multirow{2}{*}{ Multigravida } & Kneeling $\mathrm{N}=102$ & 43 & 41 & 14 & 4 & $23.48 \pm 12.32$ & \multirow{2}{*}{-16.09} \\
\hline & Supine $N=64$ & 7 & 15 & 27 & 15 & $39.38 \pm 15.37$ & \\
\hline \multirow{2}{*}{ Overall } & Kneeling $\mathrm{N}=150$ & 51 & 66 & 20 & 13 & $23.93 \pm 12.87$ & \multirow{2}{*}{-14.901} \\
\hline & Supine N=150 & 14 & 35 & 49 & 52 & $39.38 \pm 15.37$ & \\
\hline
\end{tabular}

Table 3: Mode of delivery in kneeling and supine group.

\begin{tabular}{|c|c|c|c|c|c|c|}
\hline Mode of delivery & \multicolumn{2}{|c|}{ Normal vaginal } & \multicolumn{2}{|c|}{ Operative vaginal } & \multicolumn{2}{|c|}{ Caesarean delivery } \\
\hline Primigravida $(\mathrm{N}=134)$ & Number & $\%$ & Number & $\%$ & Number & $\%$ \\
\hline Kneeling $\mathrm{N}=48$ & 43 & $89.6 \%$ & 4 & $8.4 \%$ & 1 & $2 \%$ \\
\hline Supine $N=86$ & 68 & $79 \%$ & 9 & $10.5 \%$ & 9 & $10.5 \%$ \\
\hline $\mathrm{RR}(95 \% \mathrm{CI})$ & \multicolumn{2}{|c|}{$2.275(0.7872-6.5831)$} & \multicolumn{2}{|c|}{$0.778(0.2263-2.734)$} & \multicolumn{2}{|c|}{$0.182(0.0223-1.483)$} \\
\hline \multicolumn{7}{|l|}{ Multigravida $(\mathrm{N}=166)$} \\
\hline Kneeling N = 102 & 98 & $96.1 \%$ & 4 & $3.9 \%$ & 0 & $0 \%$ \\
\hline Supine $N=64$ & 60 & $93.7 \%$ & 4 & $6.3 \%$ & 0 & $0 \%$ \\
\hline $\mathrm{RR}(95 \% \mathrm{CI})$ & \multicolumn{2}{|c|}{$1.633(0.393-6.775)$} & \multicolumn{2}{|c|}{$0.612(0.147-2.539)$} & \multicolumn{2}{|l|}{-} \\
\hline
\end{tabular}

Table 4: $2^{\text {nd }}$ degree perineal tears in kneeling and supine group.

\begin{tabular}{|c|c|c|c|c|c|c|}
\hline \multirow{3}{*}{ Parity } & & \multicolumn{4}{|c|}{$2^{\text {nd }}$ degree perineal tear } & \multirow{3}{*}{$\mathbf{R R}(95 \% \mathbf{C I})$} \\
\hline & & \multicolumn{2}{|c|}{ Present } & \multicolumn{2}{|l|}{ Absent } & \\
\hline & & Number & $\%$ & Number & $\%$ & \\
\hline \multirow{2}{*}{$\begin{array}{l}\text { Primigravida } \\
N=134\end{array}$} & Kneeling N=48 & 13 & $27.1 \%$ & 35 & $72.9 \%$ & \multirow{2}{*}{$\begin{array}{l}4.191 \\
(1.54 \text { to } 11.41)\end{array}$} \\
\hline & Supine $\mathrm{N}=86$ & 7 & $8.1 \%$ & 79 & $91.9 \%$ & \\
\hline \multirow{2}{*}{$\begin{array}{l}\text { Multigravida } \\
\mathrm{N}=166\end{array}$} & Kneeling $\mathrm{N}=102$ & 5 & $4.9 \%$ & 97 & $95.1 \%$ & \multirow{2}{*}{$\begin{array}{l}1.597 \\
(0.30 \text { to } 8.493)\end{array}$} \\
\hline & Supine $N=64$ & 2 & $3.1 \%$ & 62 & $96.9 \%$ & \\
\hline
\end{tabular}

Table 5: Apgar score at 5 minutes and NICU admissions in kneeling and supine group.

\begin{tabular}{|c|c|c|c|c|c|}
\hline \multirow{2}{*}{ APGAR at 5 minutes } & \multicolumn{2}{|l|}{ Kneeling } & \multicolumn{2}{|l|}{ Supine } & \multirow{2}{*}{$\mathbf{R R}(95 \% \mathbf{C I})$} \\
\hline & Number & $\%$ & Number & $\%$ & \\
\hline $0-3(\mathrm{~N}=28)$ & 12 & $42.86 \%$ & 16 & $57.14 \%$ & $0.728(0.332$ to 1.5972$)$ \\
\hline $4-6(\mathrm{~N}=21)$ & 10 & $47.62 \%$ & 11 & $52.38 \%$ & $0.9026(0.3714$ to 2.1935$)$ \\
\hline $7-9(N=251)$ & 128 & $51 \%$ & 123 & $49 \%$ & $1.2772(0.6905$ to 2.3622$)$ \\
\hline \multicolumn{6}{|l|}{ NICU admission } \\
\hline Yes $(\mathrm{N}=19)$ & 4 & $21.1 \%$ & 15 & $78.9 \%$ & \multirow{2}{*}{$0.246(0.079$ to 0.761$) ; \mathrm{p}=0.016$} \\
\hline No $(\mathrm{N}=281)$ & 146 & $51.96 \%$ & 135 & $48.04 \%$ & \\
\hline
\end{tabular}


No difference in Apgar scores $>7$ at 5 minutes was observed in both groups, RR $1.2772,95 \%$ CI (0.6905 to 2.3622), however, the incidence of NICU admissions was lower in the kneeling group, RR-0.246; $95 \%$ CI 0.079 to 0.761 , Table 5. There was no difference in the birth weight of babies admitted in NICU in the kneeling and supine groups, Table 6.

Table 6: Birth weight of babies admitted in NICU in kneeling and supine group.

\begin{tabular}{|c|c|c|c|c|c|c|c|}
\hline \multirow{3}{*}{ NICU admission } & \multicolumn{6}{|c|}{ Baby weight } & \multirow{3}{*}{ P value } \\
\hline & \multicolumn{2}{|c|}{$<2.5 \mathrm{~kg}$} & \multicolumn{2}{|c|}{$2.5-3 \mathrm{~kg}$} & \multicolumn{2}{|c|}{$3-3.5 \mathrm{~kg}$} & \\
\hline & $\mathrm{N}$ & $\%$ & $\mathrm{~N}$ & $\%$ & $\mathrm{~N}$ & $\%$ & \\
\hline Kneeling position $(\mathrm{N}=4)$ & 2 & $50.0 \%$ & 2 & $50.0 \%$ & 0 & - & $P=0.6133$ \\
\hline Supine position $(\mathrm{N}=15)$ & 8 & $53.3 \%$ & 4 & $26.7 \%$ & 3 & $20.0 \%$ & $\mathrm{P}=0.3502$ \\
\hline
\end{tabular}

Table 7: Patient satisfaction (by Likert's scale) in kneeling and supine group.

\begin{tabular}{|c|c|c|c|c|c|c|c|}
\hline Parity & $\begin{array}{l}\text { Patient } \\
\text { satisfaction }\end{array}$ & $\begin{array}{l}\text { Very } \\
\text { dissatisfied }\end{array}$ & Dissatisfied & $\begin{array}{l}\text { Moderately } \\
\text { satisfied }\end{array}$ & Satisfied & $\begin{array}{l}\text { Very } \\
\text { satisfied }\end{array}$ & $\mathbf{P}$ \\
\hline \multirow{4}{*}{$\begin{array}{l}\text { Primi- } \\
\text { gravida } \\
\mathrm{N}=134\end{array}$} & Kneeling (n) & 7 & 10 & 8 & 14 & 9 & \multirow{4}{*}{0.278} \\
\hline & $\%$ & $14.58 \%$ & $20.83 \%$ & $16.67 \%$ & $29.17 \%$ & $18.75 \%$ & \\
\hline & Supine (n) & 25 & 20 & 8 & 18 & 15 & \\
\hline & $\%$ & $29.07 \%$ & $23.26 \%$ & $9.30 \%$ & $20.93 \%$ & $17.44 \%$ & \\
\hline \multirow{4}{*}{$\begin{array}{l}\text { Multi- } \\
\text { gravida } \\
\mathrm{N}=166\end{array}$} & Kneeling (n) & 21 & 17 & 10 & 29 & 26 & \multirow{4}{*}{0.244} \\
\hline & $\%$ & $20.39 \%$ & $16.50 \%$ & $9.71 \%$ & $28.16 \%$ & $25.24 \%$ & \\
\hline & Supine (n) & 10 & 17 & 7 & 10 & 19 & \\
\hline & $\%$ & $15.87 \%$ & $26.98 \%$ & $11.11 \%$ & $15.87 \%$ & $30.16 \%$ & \\
\hline
\end{tabular}

Overall, $64.59 \%$ primigravida and $63.11 \%$ multigravida women were satisfied to deliver in the kneeling position. There was no difference in the satisfaction scores of primigravidae and multigravidae in both supine and kneeling position, $\mathrm{p}=0.278$ and $\mathrm{p}=0.244$, respectively, Table 7.

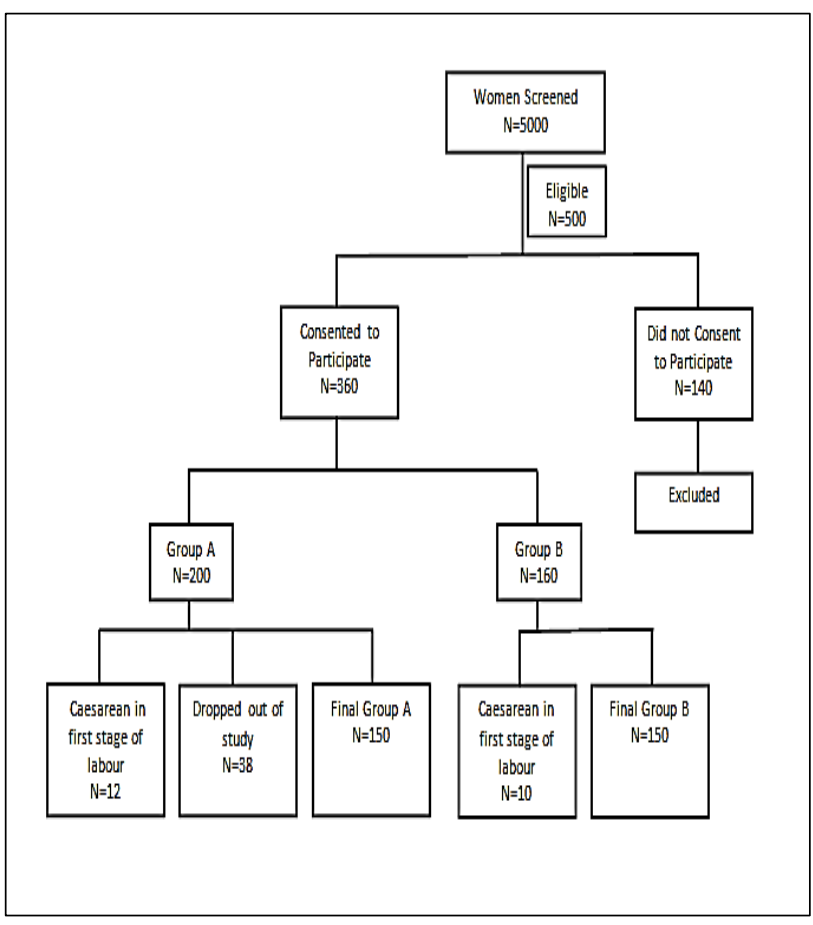

Figure 2: Recruitment of women in the study.

\section{DISCUSSION}

Delivering parturient in supine position though convenient for the care provider may not be acceptable to most women. Many authors have found upright positions to be associated with shorter second stage of labour, less operative deliveries, better neonatal outcome and positive labour experience as compared to traditional supine or lateral positions. ${ }^{1,2,4-7}$ However this observation is not consistent with some authors reporting no difference or longer duration of second stage of labour and similar operative delivery rate and neonatal outcome with upright position during labour. ${ }^{9-14}$ Most of the studies combined all upright positions for analysis of maternal and foetal outcome. Out of the various upright positions described kneeling is reported to be more comfortable by the parturient. $^{8}$

There are not many studies comparing the kneeling on knees only position with delivery in supine position during second stage of labour. Most authors have studied squatting, sitting on birth chairs or stools, standing or kneeling on all four limbs. ${ }^{6}$ Kneeling on all four limbs in our opinion is not truly an upright position as the advantage of gravitational force and alignment of fetus with the birth canal is lost with forward bending.

In the present study 38/200, $19 \%$ women opted out of the kneeling group as they were not comfortable in that position, this is higher than the $8 \%$ dropout rate reported by Regnar et al but lower than $49 \%$ reported by Gardosi et al. ${ }^{8,9}$ The duration of second stage of labour in the 
present study was shorter by 14.90 minutes, 12.17 minutes in primigravidas and 16.09 minutes in multigravidas. Similar observations have been reported by other authors with mean difference of second stage of labour by 5 to 30 minutes in upright versus supine group. ${ }^{15-20}$ However, some authors failed to observe any change in the second stage of labour whereas longer labour duration has also been reported by others. ${ }^{9-14}$ Cochrane pregnancy childbirth systemic review of randomized trials by Gupta et al reported a small but significant decrease of second stage duration in women delivering in the upright position (all combined) compared to supine position, - 6.16; 95\% CI - 9.74, 2.59. ${ }^{21}$ However, Bhardwaj et al showed significant reduction in the duration of second stage of labour in the upright position, 21.2 versus 39.32 minutes, $\mathrm{p}=0.01 .^{20}$ This may be attributed to Indian women being used to upright positions during their daily activities.

Moraloglu et al also reported delivering in squatting position to be more comfortable in Turkish women who are also used to sitting in this position. ${ }^{16}$ The Cochrane review 2017 also observed the duration of labour to be reduced by -10.64 minutes; $95 \%$ CI -20.15 to -1.12 , in women using birth cushions for delivery compared to supine position. ${ }^{21}$

The present study found a difference in favor of normal vaginal delivery and a decrease in the operative vaginal delivery in the kneeling position compared to the supine position; however, the difference was not statistically significant. The increased normal vaginal delivery rate in the kneeling position may be because of more efficient uterine contractions in the kneeling position, increased anteroposterior outlet diameter and transverse outlet diameter reported in the upright position. .,2,4,6,7 $^{1}$

The normal vaginal delivery rate among primigravida women was found to be higher in the kneeling group, $89.6 \%$ versus $79.1 \%$, RR-2.275; 95\% CI 0.7872 to 6.5831. Though the caesarean delivery rates were decreased in kneeling group $2 \%$ vs $10.5 \%$ in supine group, RR-0.1820; 95\% CI 0.02234 to 1.483 , the difference was not statistically significant. Similarly, the operative vaginal delivery risk was not significantly different between the two groups, RR $0.778 ; 95 \%$ CI 0.2263 to 2.734 .

Amongst the multigravida the difference in normal vaginal delivery rate in kneeling versus supine group was not statistically significant, $96.1 \%$ and $93.75 \%$ respectively, RR-1.633; 95\% CI 0.393 to 6.775 . The rate of operative vaginal delivery was lower in the kneeling group $3.9 \%$ vs $6.3 \%$, RR-0.612; $95 \%$ CI 0.147 to 2.539 , but not significantly different. None of the multigravida women in the present study had caesarean delivery.

Most of the earlier studies have found significant reduction in operative vaginal delivery rates in upright position. ${ }^{6,17,19,21,22}$ Studies have failed to report significant difference in the caesarean section rate among women delivering in upright and supine position. ${ }^{10-14,17,22-26}$ Gupta et al also didn't find any significant reduction in the caesarean section rate, RR $1.22 ; 95 \%$ CI 0.81 to $1.81 .^{21}$

\section{Incidence of perineal tears}

A policy of selective episiotomy was followed in the present study, as a result first degree tears were quite common and therefore the incidence of first degree tears is not reported. We observed an increased incidence of second degree perineal tears in primigravida women delivering in the kneeling position. This has been attributed to more anteriorly placed head with relatively rigid perineum in primigravidas and comparative inability to provide perineal support in Kneeling position. There are similar reports of increase in second degree tears in upright ${ }^{11,17,25}$ while some authors have reported more tears in supine position. ${ }^{20,27}$ Cochrane review 2017 didn't find increased risk of second degree perineal tears in the upright position, RR 1.20; 95\% CI 1.00 to 1.44 . However they reported fewer second degree tears among women delivering on birth cushions compared to supine position, RR 0.72 (95\% CI 0.54 to 0.97$).{ }^{21}$

\section{Foetal and neonatal outcome}

On comparing both groups no difference was found in the Apgar score at 5 minutes. Our observations are similar to Terry et al who also reported insignificant difference in Apgar at 1 and 5 minutes in infants of women delivered in upright position as compared to supine position. ${ }^{27}$ However, the present study observed significant difference in the NICU admission rate between the two groups. There were 19 NICU admissions out of these $21.1 \%$ babies delivered in kneeling compared to $78.9 \%$ in supine position, RR-0.246; $95 \%$ CI 0.079 to 0.761 . Women delivering in supine position are thought to have more chances of birth asphyxia during active pushing. This is due to the decrease in uteroplacental perfusion which is aggravated in the supine position due to added aortacaval compression. ${ }^{3}$ However, Crowley et al and Walderstorm et al didn't find any significant difference in the NICU admission rate. ${ }^{11,12}$

\section{Patient's satisfaction}

There was no difference in the satisfaction level of women delivering in kneeling and supine position. Nevertheless primigravidas showed better adherence to the kneeling position and cooperated because it was their first exposure to delivery. It was more difficult to explain the kneeling position to multigravida women who had previously delivered in the supine position and thus there was more difficulty in ensuring their adherence to the position. Two Indian studies have reported more patient satisfaction and positive experience with upright positions but de Jong et al could not find significant difference in satisfaction among women delivering in upright and supine positions. ${ }^{19,20,24}$ It is advised that 
women should be exposed to all types of positions so that they can choose the position they are most comfortable in.

The strength of our study is that all women in upright group delivered in only one upright position and all deliveries were conducted by one resident who was motivated and trained to deliver women in the kneeling position. The weakness of our study is the small sample size and that the women were recruited in the study during labour. Therefore, the dropout rate was higher in the kneeling group. These women could have adhered to the position if motivation and training was started in the antenatal period.

\section{CONCLUSION}

Women delivering in kneeling position have an overall shorter duration of second stage of labour and lesser neonatal intensive care unit admissions compared to supine position. On the other hand, the risk of second degree perineal tears is increased in primigravidas delivering in kneeling position. Primigravidas have better adherence to the kneeling position

\section{Recommendations}

We recommend that medical personnel should be given enough exposure and be trained in conducting delivery in the kneeling upright position as it is a positive intervention to decrease foetal morbidity and NICU admission rate, this will reduce the burden on infrastructure in resource limited countries. However, to further validate this observation studies with larger sample size should be conducted.

Funding: No funding sources Conflict of interest: None declared

Ethical approval: The study was approved by the Institutional Ethics Committee

\section{REFERENCES}

1. Munro J, Jokinen M, Gutteridge K, Macdonald S, Day-Stirk F. The Royal College of Midwives' Survey of positions used in labour and birth. London: Royal College of Midwives (RCM) 2010.

2. Lavender T Mlay R. Position in the second stage of labour for women without epidural anesthesia: RHL commentary (last revised: 15 December 2006). The WHO Reproductive Health Library; Geneva: World Health Organization.

3. Kerr MG, Scott DB, Samuel E. Studies of the Inferior Vena Cava in Late Pregnancy. Br Med J 1964;1(5382):522-4, 532-533.

4. Caldeyro-Barcia R, Noriega-Guerra L, Cibils LA, Alvarez H, Poseiro JJ, Pose SV, et al. Effect of position changes on the intensity and frequency of uterine contractions during labor. Am J Obstet Gynecol 1960;80(2):284- 90.
5. Méndez-Bauer C, Arroyo J, García Ramos C, Menéndez A, Lavilla M, Izquierdo F, et al. Effects of standing position on spontaneous uterine contractility and other aspects of labor. J Perinat Med 1975;3(2):89-100.

6. Gupta JK, Hofmeyr GJ, Shehmar M. Position in the second stage of labour for women without epidural anaesthesia. Cochrane Database Syst Rev 2012 May 16;(5):CD002006. doi: 10.1002/14651858.

7. Gupta JK, Glanville JN, Johnson N, Lilford RJ, Dunham RJ, Watters JK. The effect of squatting on pelvic dimensions. Eur J Obstet Gynecol Reprod Biol 1991;42(1):19-22.

8. Ragnar I, Altman D, Tydén T, Olsson SE. Comparison of the maternal experience and duration of labour in two upright delivery positions--a randomised controlled trial. BJOG 2006;113(2):16570.

9. Gardosi J, Sylvester S, B-Lynch C. Alternative positions in the second stage of labour: a randomized controlled trial. $\mathrm{Br} \mathrm{J}$ Obstet Gynaecol 1989;96(11):1290-6.

10. Stewart P, Spiby H. A randomized study of the sitting position for delivery using a newly designed obstetric chair. BJOG 1989;96(3):327-33.

11. Crowley P, Elbourne D, Ashurst H, Garcia J, Murphy D, Duignan N. Delivery in an obstetric birth chair: a randomized controlled trial. BJOG 1991;98(7):667-74.

12. Waldenström U, Gottvall K. A randomized trial of birthing stool or conventional semirecumbent position for second-stage labor. Birth. 1991;18(1):510.

13. Bomfim-Hyppólito S. Influence of the position of the mother at delivery over some maternal and neonatal outcomes. Int J Gynaecol Obstet. 1998;63 Suppl 1:S67-73.

14. Racinet C, Eymery P, Philibert L, Lucas C. Labor in the squatting position. [A randomized trial comparing the squatting position with the classical position for the expulsion phase] [abstract]. J Gynecol Obstet Biol Reprod (Paris). 1999;28(3):26370 .

15. Jahanfar S, Amini L, Jamshidi R. Third and fourth stages of labour: sitting position. BJM 2004;12(7):437-46.

16. Moraloglu O, Kansu-Celik H, Tasci Y, Karakaya BK, Yilmaz Y, Cakir E, et al. The influence of different maternal pushing positions on birth outcomes at the second stage of labor in nulliparous women. J Matern Fetal Neonatal Med 2017;30(2):245-9.

17. Gardosi J, Hutson N, B-Lynch C. Randomised, controlled trial of squatting in the second stage of labour. Lancet 1989;2(8654):74-7.

18. Suwanakam S, Linasmita V, Phuapradit W, Pongruengphant $\mathrm{P}$. The effects of sitting position on the second stage of labor. J Med Assoc Thai 1988;71(Suppl 1):72-5. 
19. Ganapathy T. Childbirth in Supported Sitting maternal position. IJONE 2012;4(2):87-91.

20. Bhardwaj N, Kukade JA, Patil S, Bhardwaj S. Randomised controlled trial on modified squatting position of delivery. Indian J Matern Child Health 1995;6(2):33-9.

21. Gupta JK, Sood A, Hofmeyr GJ, Vogel JP. Position in the second stage of labour for women without epidural anaesthesia. Cochrane Database Syst Rev 2017;5:CD002006. doi: 10.1002/14651858.

22. Nasir A, Korejo R, Noorani KJ. Child birth in squatting position. J Pak Med Assoc. 2007;57(1):1922.

23. Radkey AL, Liston RM, Scott KE, Young C. Squatting: Preventive medicine in childbirth? [abstract]. In: Proceedings of the annual meeting of the Society of Obstetricians and Gynaecologists of Canada. Toronto: Canada, 1991:76.

24. de Jong PR, Johanson RB, Baxen P, Adrians VD, van der Westhuisen S, Jones PW. Randomised trial comparing the upright and supine positions for the second stage of labour. Br J Obstet Gynaecol. 1997;104(5):567-71.

25. Turner MJ, Romney ML, Webb JB, Gordon H. The birthing chair: an obstetric hazard? J Obstet Gynaecol 1986;6:232-5.

26. Allahbadia GN, Vaidya PR. Why deliver in the supine position? Aust N Z J Obstet Gynaecol. 1992;32(2):104-6.

27. Terry RR, Westcott J, O'Shea L, Kelly F. Postpartum outcomes in supine delivery by physicians vs nonsupine delivery by midwives. J Am Osteopath Assoc. 2006;106(4):199-202.

Cite this article as: Dabral A, Pawar P, Bharti R, Kumari A, Batra A, Arora R. Upright kneeling position during second stage of labor: a pilot study. Int J Reprod Contracept Obstet Gynecol 2018;7:4017. 